Article

\title{
Remnant Coal Detection System
}

\author{
Chad Hargrave* and Paul McPhee \\ CSIRO, 1 Technology Court, Pullenvale QLD 4069, Australia; Paul.Mcphee@csiro.au \\ * Correspondence: chad.hargrave@csiro.au
}

Received: 5 March 2020; Accepted: 14 April 2020; Published: 17 April 2020

check for updates

\begin{abstract}
This paper describes the development and successful implementation of a system designed to detect coal deposits remaining in coal train wagons after unloading (dumping). These undesirable coal deposits constitute both small residual amounts of "carryback", but also larger "hang-ups" of significant volume that have failed to discharge. The system was originally developed simply to detect and record volumes of carryback, as part of an effort to characterise the extent of the problem for the coal transport industry, but was then enhanced to provide real-time feedback of large hang-ups so that they could be discharged prior to the wagons exiting the dump station. The paper describes the hardware and processing systems used in the system, including the different strategies employed to ensure a reliable detection system. The system has now been installed and operated in a production environment at three dump stations across two different coal terminals, and a case study of the results from one of these dump stations is presented. Automating remnant coal detection at dump stations provides short interval control to minimise potential hazards and downtime, and historical data that may be integrated into existing data platforms and analysed for productivity, environmental, and safety planning insights.
\end{abstract}

Keywords: coal; train; unloading; carryback; remnant; detection

\section{Introduction}

To maintain efficiency and hence maximise productivity, unloading dump stations at coal terminals must discharge all coal in the incoming wagons, if possible, without stopping the train, and certainly before a given wagon passes by the last unloading pit. If wagons fail to dump their coal in time, due to coal remaining lodged in the wagon (so-called "sticky coal" hang-ups) and the wagon exits the station, a potentially dangerous situation will arise, as the coal may dislodge at a later time, fouling tracks and ballast, and even, in some cases, derailing the train [1]. Even if the coal hang-up is seen after the wagon has passed beyond the final pit, a costly exercise in reversing the train will ensue that will cost the dump station productive time.

Smaller volumes of residual coal, known as carryback, are also the cause of many problems for mines and ports alike. Carryback is responsible for reducing wagon capacity for future loading, causing cross contamination of coal types, increasing coal dust pollution in population centres near train lines, and, in some cases, causing derailments due to spillage of remnant coal onto the tracks [2,3]. Effective management of carryback is thus a high priority with clear benefits in terms of productivity, safety, and environmental control. The first requirement for effective control of carryback is a reliable and accurate system that can detect and quantify the level of post-dump remnant coal in coal wagons. The object of the research project described herein was to develop a system capable of detecting coal carryback and alerting the operator in time to allow the remnant coal to be dislodged before the wagon exits the final pit of the dump station.

Australia's national research organisation, the Commonwealth Scientific and Industrial Research Organisation (CSIRO), works closely with the coal industry to develop solutions for a wide variety of 
operational and production challenges. A previous CSIRO research effort related to the measurement of haul truck load volumes had demonstrated the efficacy of laser-scanning (lidar) technologies for industrial load monitoring [4], with the resulting system successfully commercialised for the case of mining haul trucks. Related research in the area of three-dimensional (3D) mapping within coal mines [5,6] has validated the application of laser-scanning sensors to the problem of volume estimation of coal targets. Accurate volume and/or surface area mapping of coal targets using lidar technology requires careful selection and configuration of measuring instruments combined with an effective algorithm to deal with complicating factors such as target aspect and related shadowing effects [7], vehicle motion [8], and alterations in vehicle velocity [9]. Various volume-estimation approaches have been trialled in a range of application domains including mining [10], agriculture [11], and forestry [12]. Lidar performance when measuring the bulk volume of dark-coloured target materials, such as coal under dusty conditions (such as typically found during loading and unloading coal), is significantly degraded, and enhanced signal processing and filtering techniques are generally required to reconstruct the load volume to the levels of accuracy required for industrial load monitoring [13,14]. The adaptation of these dynamic bulk measurement techniques to the conditions encountered in a coal unloading facility was the subject of an extended research and development campaign by CSIRO. The proposed approach for this research was to employ a two-dimensional (2D) scanning lidar to acquire sequential line profiles across coal rail wagons, perpendicular to the direction of travel. Each profile represents a 2D area, which can then be integrated into a 3D volume using the measured speed of the train. The details of the method are described in Section 2 of this paper.

An initial research project was funded by the Australian Coal Association Research Program (ACARP) to investigate the extent of carryback present in coal wagons from various central Queensland coal mines. This project developed a new wagon inspection system that was employed at a coal terminal in Gladstone on the central Queensland coast. The detection system was designed to scan the coal wagons after dumping using a two-dimensional (2D) laser scanner (lidar), and then analyse the resulting data to estimate the extent and distribution of the carryback for each wagon. This research project culminated in a six-month survey of all wagons emptying at one of the terminal's three dump stations, and delivered a statistically robust picture of the extent and variation of carryback across the Bowen Basin mines that shipped product via Gladstone [15]. Beyond the immediate benefit, the data collected and analysed by the system may contribute to the wider mining value chain, informing improved processes at both the mine and port stages of operation.

Based on the success of this ACARP carryback project, the coal terminal engaged CSIRO directly to develop a real-time detection system based on the same laser sensing technology. This Remnant Coal Detection (RCD) technology provides an early warning system that identifies the presence of sticky coal hang-ups in the wagon (Figure 1), and then provides an alert (either directly to the train control system or via an alarm to the operator) in time for the train to be stopped prior to the final pit, allowing cleaning to take place. The technology allows for volume threshold levels to be set, so that the alert is issued only for hang-ups of a sufficient size to demand dislodgement, as determined by the coal terminal. When combined with a wagon identification system, the RCD technology can also perform accurate coal volume measurement on the loaded coal train wagons as they enter the unloading facility, providing important new data for the coal terminal that will improve stockpile management. Because the RCD technology also identifies the location of the hang-ups within each wagon, the system is ideally suited to be combined with an automated cleaning system. 


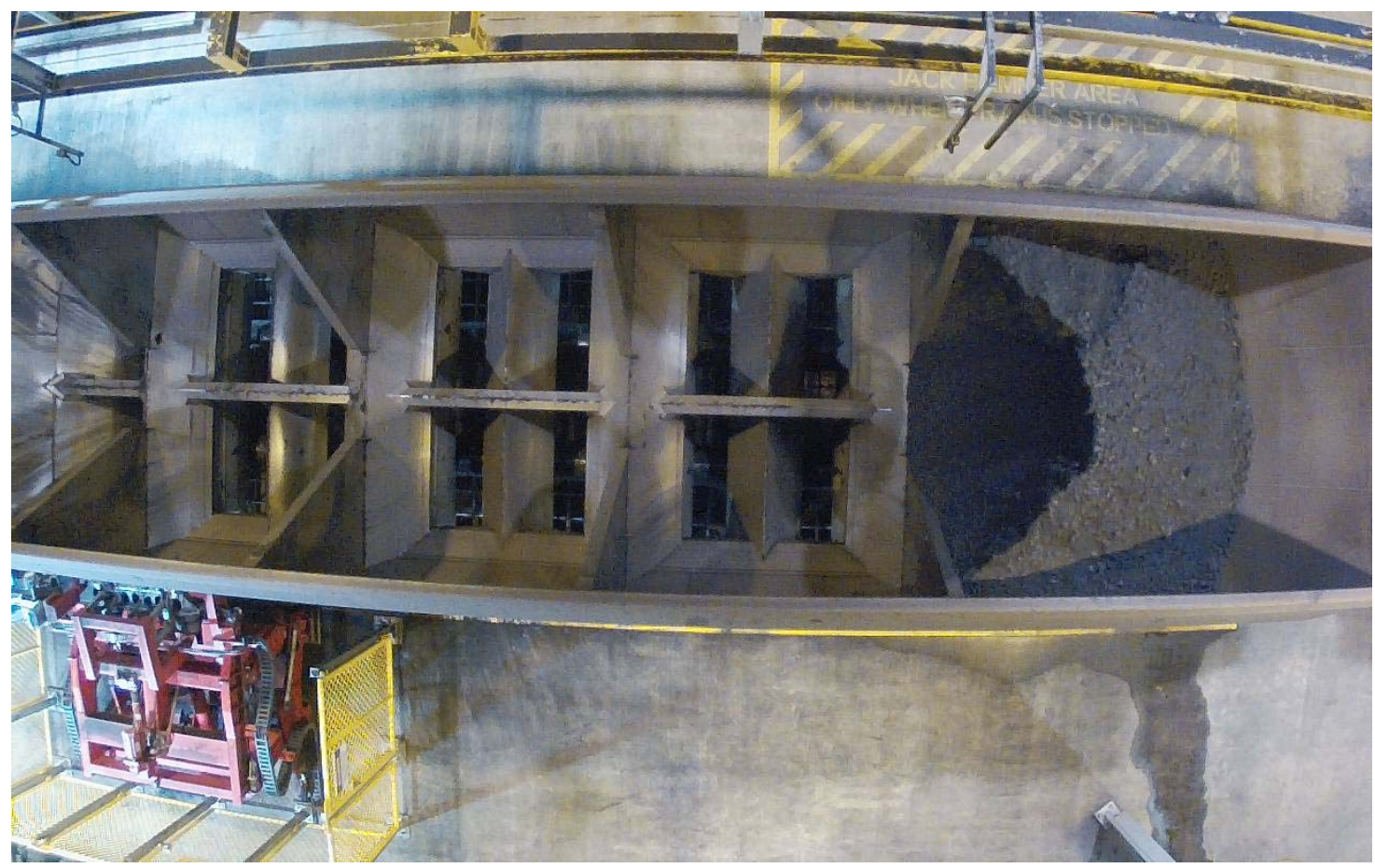

Figure 1. Coal hang-up in front compartment of wagon.

\section{Materials and Methods}

\subsection{Carryback Project}

A system for measurement and off-line analysis of carryback was developed during the original ACARP project and was at a Gladstone coal terminal dump station. This system included the following components:

- Two 2D laser scanners mounted above the rail line (Figure 2);

- An acquisition and analysis computer housed within the dump station control room;

- Online software for data acquisition and storage;

- Offline analysis software for summarising the results.

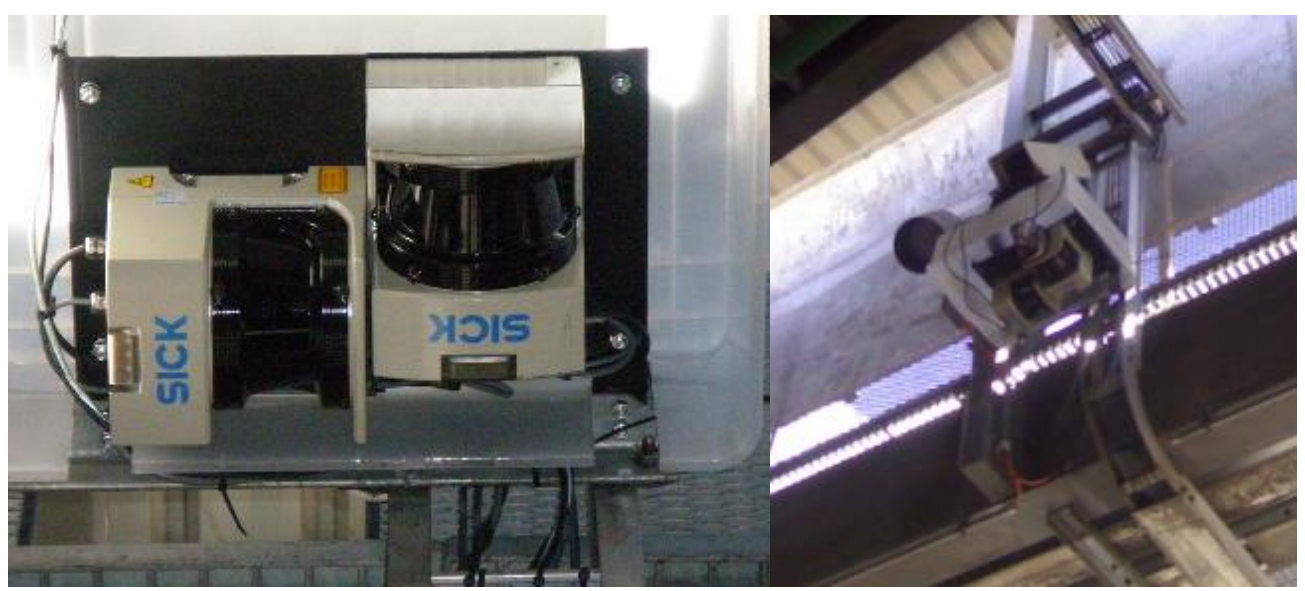

Figure 2. Overhead laser scanners mounted at a coal terminal dump station.

A laser scanner can be used to estimate the distance to a surface within its field of view. The transverse laser scanner (relative to the rail line) provides a series of $2 \mathrm{D}$ cross-sectional scans that 
provide a detailed view of the interior of the coal wagons (Figure 3). Because of the movement of the train, multiple scans can be accumulated to develop a three-dimensional profile of the wagon (Figure 4). If a wagon passes under a scanner and the wagon's instantaneous speed is known, then the wagon's interior volume can be estimated. Two scanners were mounted at the dump station as shown in Figure 2. The second scanner is used for wagon speed estimation.

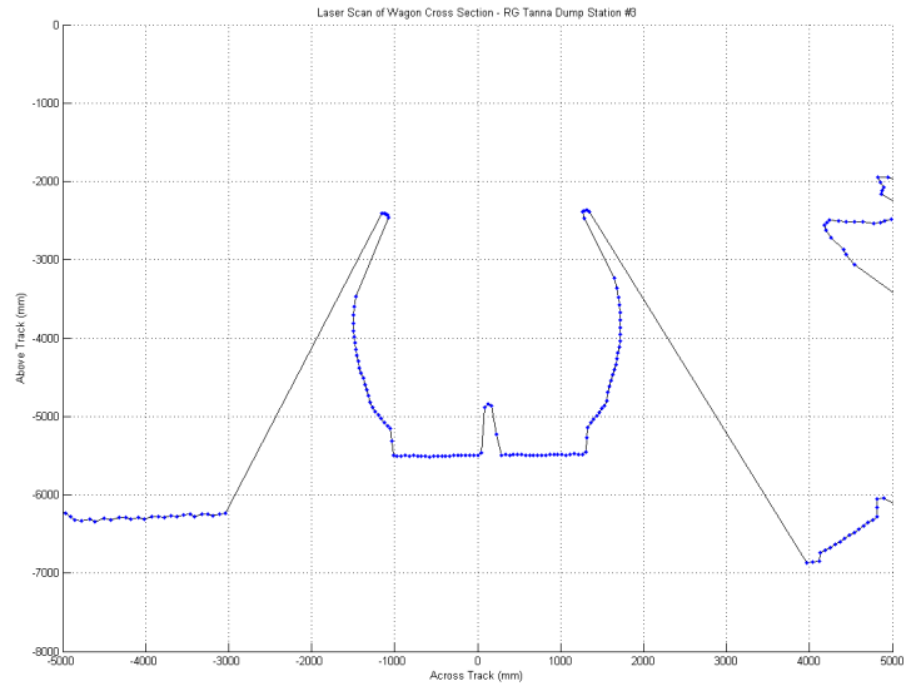

Figure 3. Single laser scan line across a coal wagon mid-section.
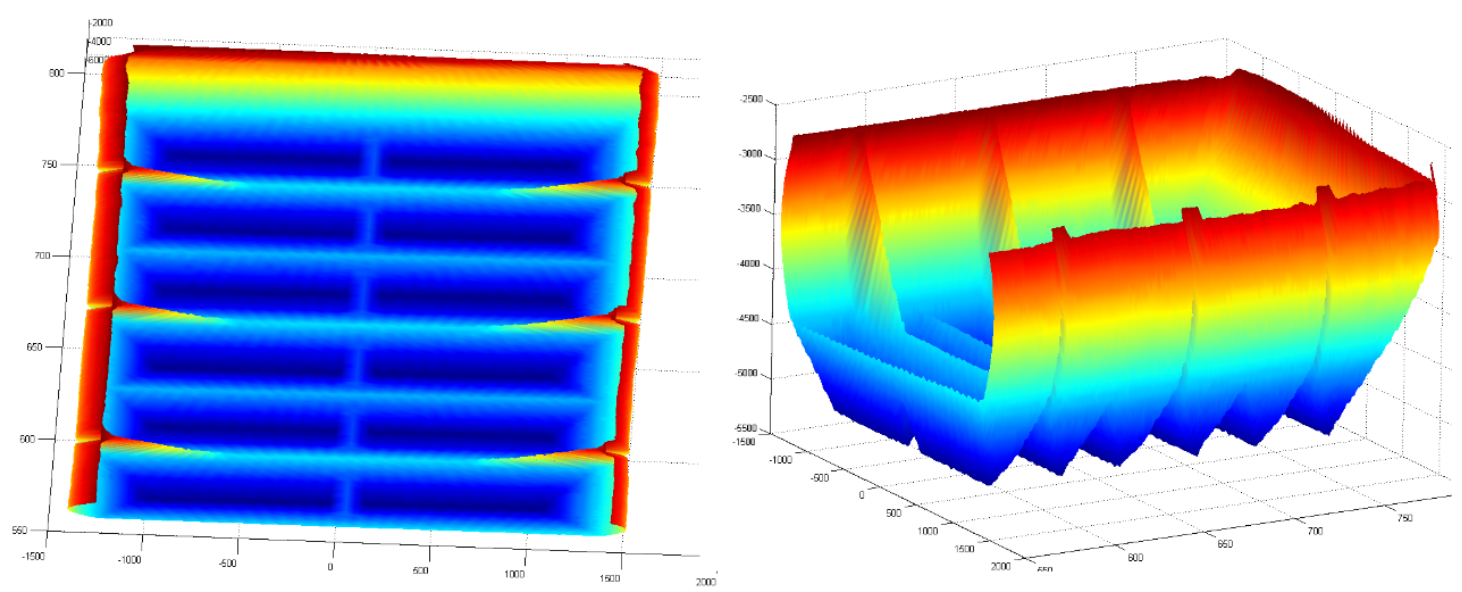

Figure 4. Reconstructed 3D views of a coal train wagon based on multiple 2D laser scan lines.

Although the primary goal of the ACARP project was to develop a statistical picture of the extent of the carryback problem, a secondary outcome was to develop a basic graphical user interface (GUI) to allow operators at the terminal to be alerted when wagons exited the dump station while still retaining significant remnant coal. The display (Figure 5) includes an alarm feature that can alert the operator with an audible tone when a significant level of carryback is detected for the current wagon. The system allows for two different levels of warning: an alert tone for smaller volumes of carryback (shown in yellow), and an alarm tone for significant volumes that require cleaning (highlighted in red). The threshold level at which the alarms are triggered can be adjusted by the user. The display also features a simplified plan view and side view of the wagon internals, to allow the operator to judge the level of severity of the carryback. Visualisation and analysis of historical data captured by the system may also contribute to the assessment of mitigation measures, and to the integrity and scope of broader integrated supply chain simulations. 


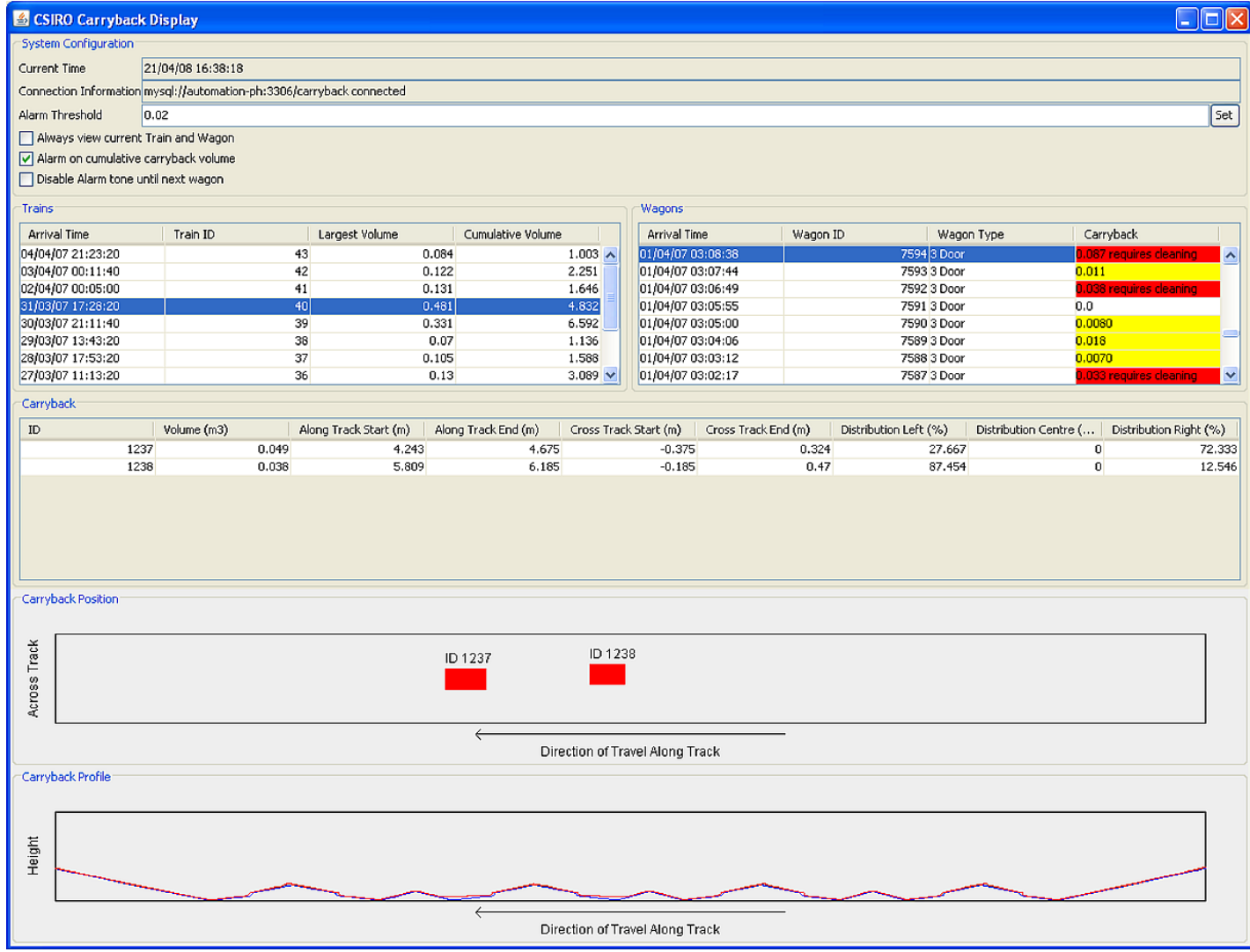

Figure 5. Operator display showing wagon profile and carryback deposit locations.

The location of the carryback is significant, because residual coal that lodges over the internal doors is more likely to leak out in transit, causing ballast pollution or even derailment. Note that the coal wagons employed in Australia are generally belly-dumpers with triggered "kwik-drop-doors" (KDDs).

\subsection{Remnant Coal Detection (RCD) System}

The RCD system was developed as an improved real-time detection system for the coal terminal operation where the original ACARP carryback project was trialled. The terminal operator identified undetected large coal hang-ups that exited the dump station as a key safety and productivity issue, and requested a system that could alert the operator to the presence of a coal hang-up prior to the wagon clearing the last pit in the dump station.

The RCD system featured an enhanced hardware construction that provided a more robust housing for the laser scanners and facilitated cleaning from the dump station floor using water jets (Figure 6).

As the train transits through the dump station, a profile of the train is produced. This profile is then processed to detect significant hang-ups. If one is found, the RCD system informs the operator via the dump station's control system. The train can then be stopped so that the hang-up can be cleared. Alternatively, the system can directly trigger a train stoppage via the train control system. Stopping the train prior to exiting the dump station is critical, as failing to do so requires that the train be reversed, resulting in both time and financial penalties.

Although the RCD system did not feature a standalone GUI (since it was designed to be integrated into the client's plant control system), a web interface (Figure 7) to the system was developed to provide the client with the ability to interrogate the historical data associated with particular trains and wagons. This interface provides access to previously scanned wagons, and includes information on the presence of hang-ups, with wagons classified according to their scanned contents as either a clear, warning, or alarm situation. Thumbnail images for each wagon are also recorded, so that operators can examine the circumstances that led to a particular warning or alarm situation, and potentially adjust 
the detection thresholds to improve the system's response in accordance with operational policy on the level of acceptable remnant coal. Each thumbnail image links to a full resolution image for closer examination if required.

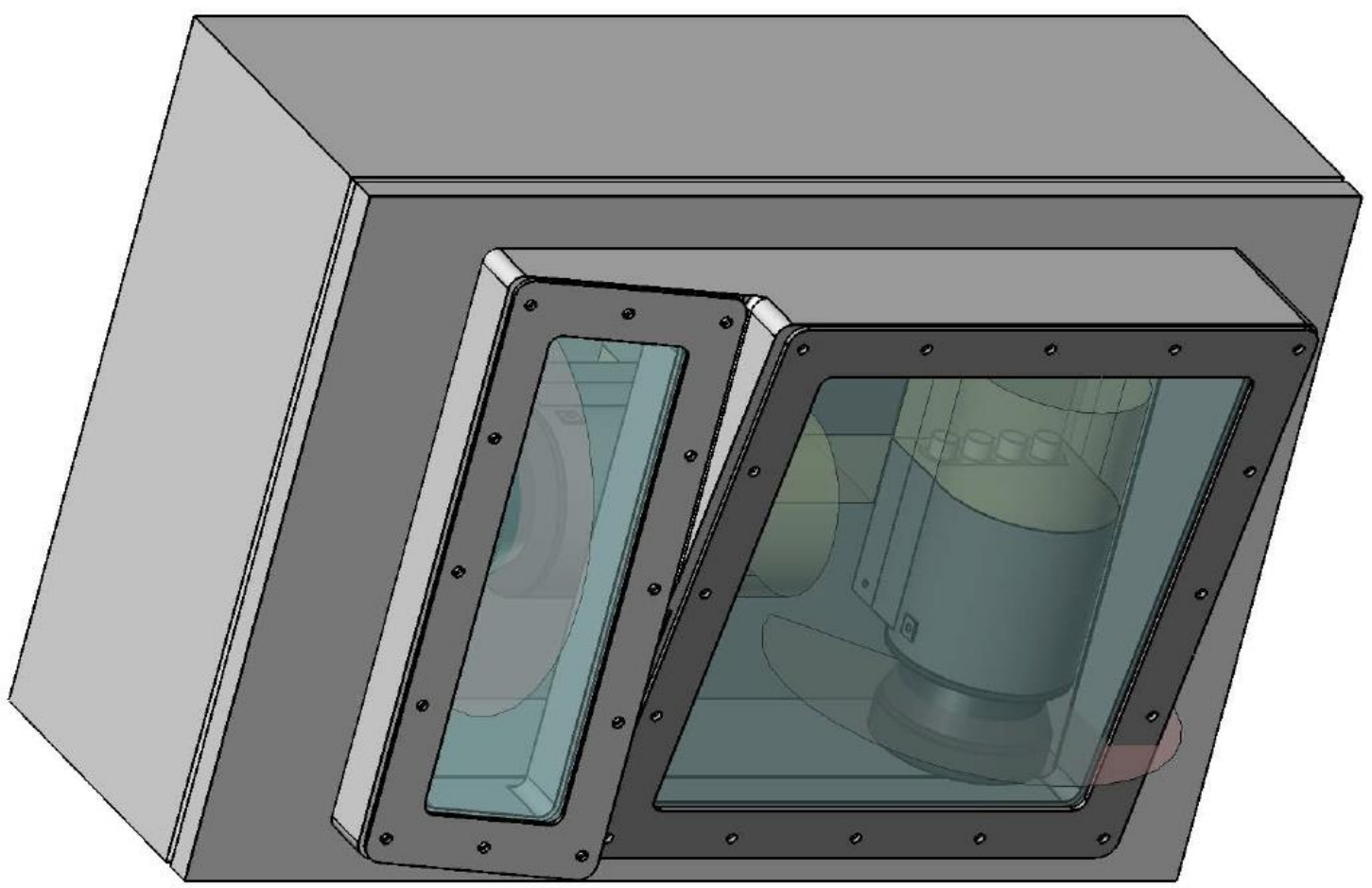

Figure 6. Remnant Coal Detection (RCD) sensor hardware.

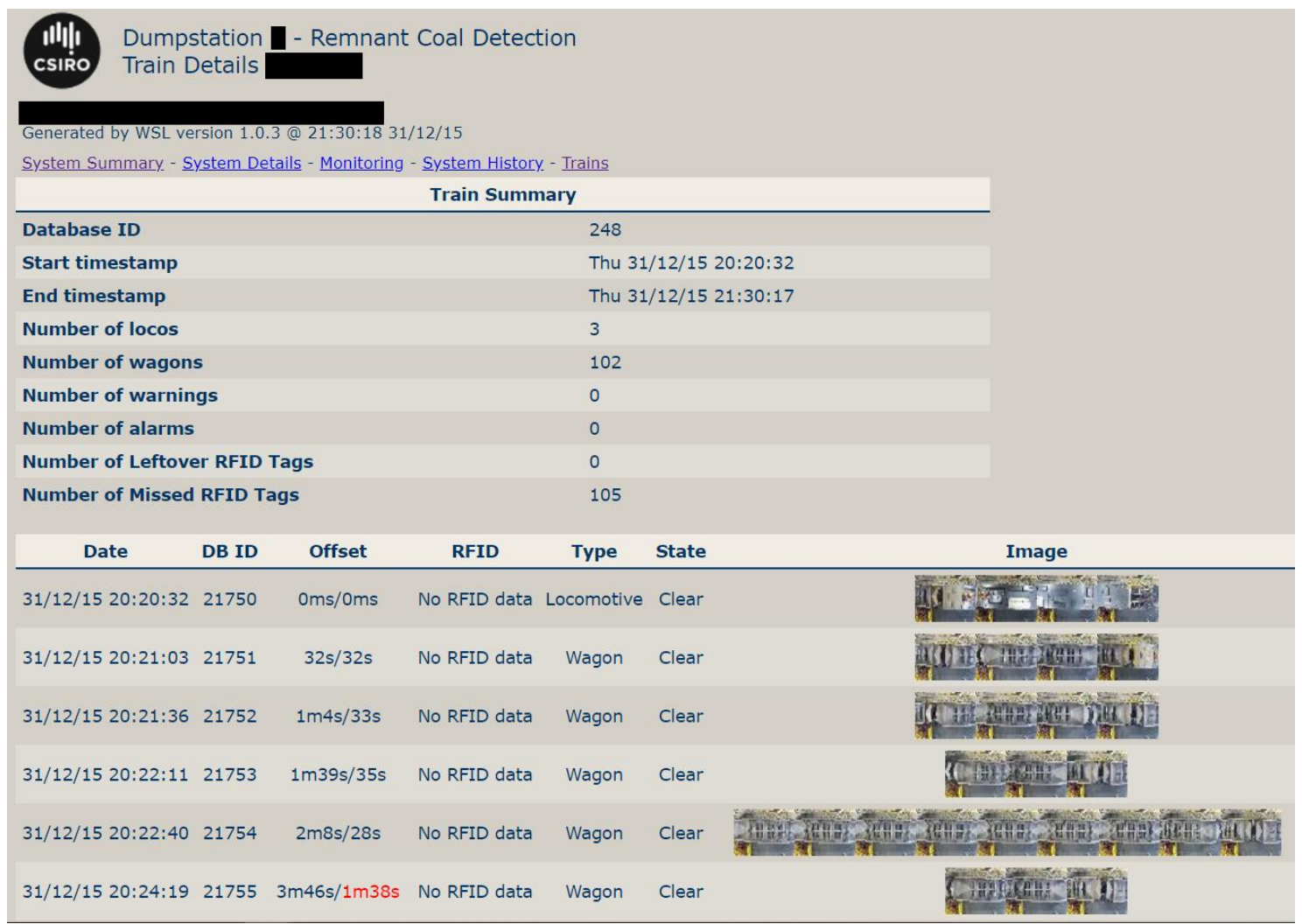

Figure 7. RCD web interface. 
The RCD system was successfully commissioned at the original coal terminal, and then duplicated at a second dump station at the same location. A third RCD system has since been installed and commissioned at a second coal terminal on the Queensland coast, where it continues to function as a 24/7 monitoring tool for the port operation.

The thumbnail and high-resolution images are taken from a camera mounted in the over-train sensor box used by the RCD system. The sensor box is positioned just before the final pit in the dumping station, and operational policy aims to have all coal emptied (or emptying) before this pit. Any hang-ups over this pit must force the stoppage of the train until the coal is dislodged.

\section{Results}

A summary of the results obtained from both the original carryback project and the RCD system development and commissioning is provided below.

\subsection{Carryback Project Results}

Two aspects of the basic carryback data have been selected for analysis: the total carryback detected per wagon, as well as the KDD carryback per wagon, which refers to occurrences of carryback where the coal is located over a wagon door. As noted in Section 2.1, coal deposits located over the KDDs are critical, as they are more prone to lead to ballast contamination or even (for larger coal volumes) potential derailment incidents.

For the six-month period of the study, the mean total carryback was 0.359 tonnes per wagon, and the mean KDD carryback was 0.049 tonnes per wagon. Based on an average train frequency of 4.5 trains per day through the dump station, this equated to a total of approximately 61,000 tonnes per year of total carryback, including approximately 8400 tonnes per year of KDD carryback. Figure 8 shows the volume distribution for the total measured carryback during the six-month survey, and Figure 9 shows the KDD carryback for the same period [15].

While the average carryback per wagon was 0.36 tonnes per wagon, this average increased dramatically to 0.93 tonnes per wagon during a two-month period in which heavy rains occurred in the region of the source coal basin. These results, including the characteristic shape of the histogram distributions, will be discussed in Section 4.

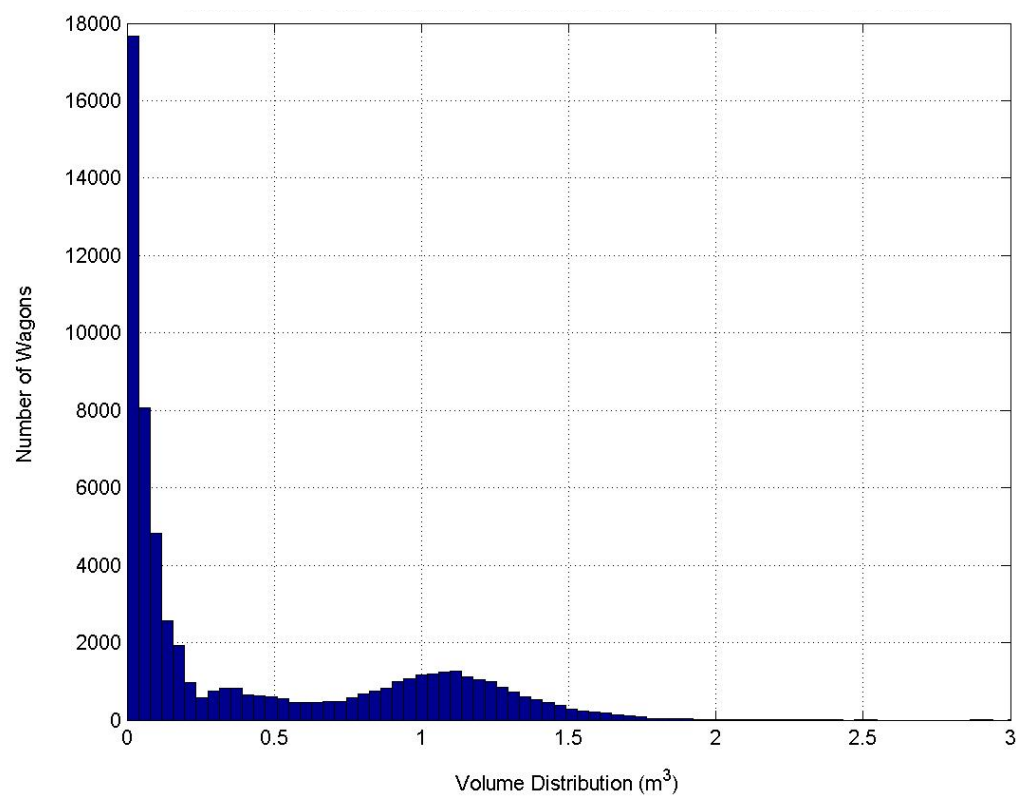

Figure 8. Distribution of total carryback volume for the six-month survey. 


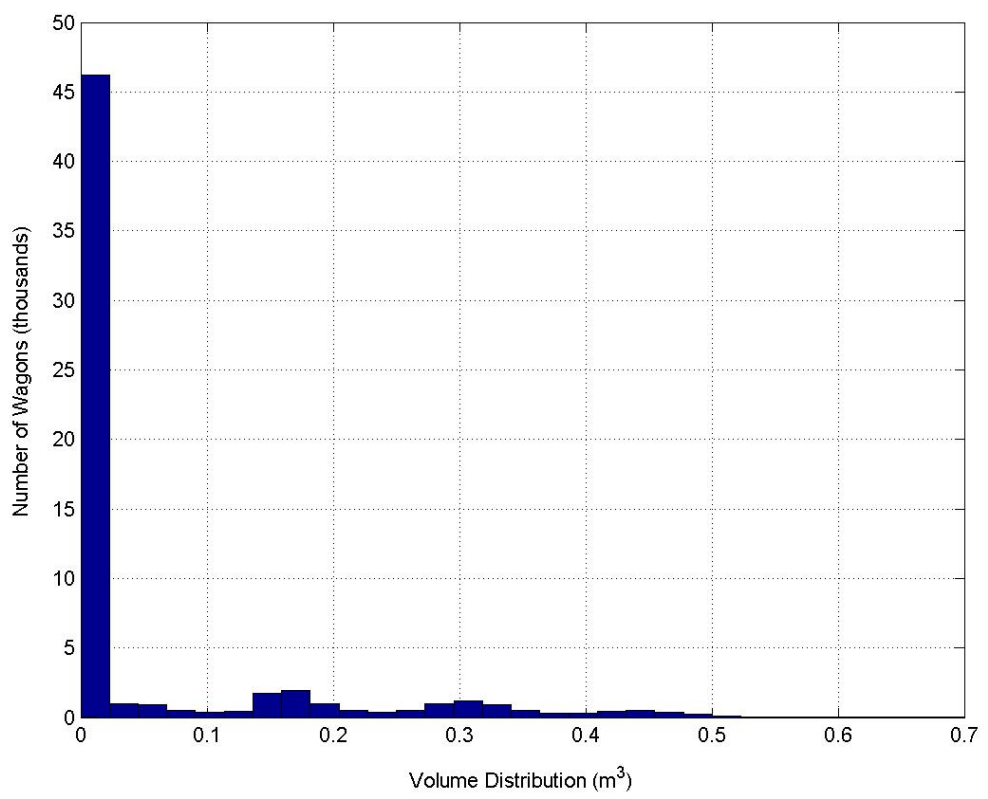

Figure 9. Distribution of kwik-drop-doors (KDD) carryback volume for the six-month survey.

\section{2. $R C D$ Project Results}

Unlike the carryback project, which was designed to deliver a statistical result, the RCD system was developed in order to perform a critical operational function at a working coal terminal. The efficacy of the system was therefore measured in terms of its ability to provide an accurate warning of a coal hang-up in a sufficiently short time period to allow the operator to react and stop the train [16].

With regard to the second aspect, the time delay to alert the operator, it was difficult to provide a quantitative measure of system performance due to the fact that the location of a particular hang-up in a wagon can vary significantly, so the time delay cannot be measured from the start of the wagon. However, by interrogating the system's database logging system, it was possible to determine that the time from the moment of detecting the possible start of a coal hang-up to the point of generating a system alarm was typically less than a second, and that the alarm would propagate to the operators' screens within 1-2 s (depending on the configuration and speed of the plant control system). This typically meant that the operator would have a period of 5-10 seconds (depending on train speed) to react to the alarm condition and alert the train to stop, which was considered to be an adequate window. For the most recent RCD installation, the system has been linked directly to the train control system so that system alarms directly trigger the stop signal to the train driver.

The most important element of the system efficacy, however, is the robustness and accuracy of the hang-up detection and measurement algorithms. These parameters are best measured in terms of true and false positive rates, and true and false negative rates. As the RCD system has been installed as an operational tool for a number of years at several dump stations, there have been numerous audits of the system performance during this time. The two most extensive of these audits to date, from two different coal terminals, are presented here as representative of the system performance.

\subsubsection{First Audit Results from Coal Terminal A}

This audit was carried out to compare the results of the RCD system's automatic hang-up detection algorithms with a manual inspection by a human operator. Historical data, logged by the RCD system from two separate dump stations at coal terminal A, was examined for three separate month-long reviews at each station. Every train and wagon image was visually examined to verify the system performance, with the results categorised as follows: 
- Hang-up warnings that were reported (True or False Positive Warnings);

- Hang-up alarms that were reported (True or False Positive Alarms);

- Hang-ups that were not reported (False Negative Alarms);

- Clear wagons correctly reported (True Negative Alarms).

The results of these audits are shown in Table 1.

Table 1. Audit Results for Coal Terminal A Review.

\begin{tabular}{cccccccc}
\hline Period & Trains & Vehicles $\mathbf{1}$ & $\begin{array}{c}\text { Total } \\
\text { Warnings }\end{array}$ & $\begin{array}{c}\text { Total } \\
\text { Alarms }\end{array}$ & $\begin{array}{c}\text { False Positive } \\
\text { Warnings }\end{array}$ & $\begin{array}{c}\text { False Positive } \\
\text { Alarms }\end{array}$ & $\begin{array}{c}\text { False Negative } \\
\text { Alarms }\end{array}$ \\
\hline DS1 9/13 & 267 & 26,548 & 34 & 87 & 1 & 5 & NA \\
DS1 10/13 & 91 & 9022 & 13 & 29 & 0 & 0 & NA \\
DS1 3/14 & 255 & 25,957 & 10 & 89 & 2 & 10 & NA \\
DS2 9/13 & 94 & 9655 & 3 & 32 & 0 & 6 & NA \\
DS2 10/13 & 224 & 22,063 & 101 & 242 & 37 & 13 & 3 \\
DS2 12/14 & 267 & 27,495 & 123 & 113 & 0 & 1 & 0 \\
\hline
\end{tabular}

${ }^{1}$ Vehicle counts include both locomotives and wagons.

The Table 1 results are shown for the two dump stations where the RCD system was operating, designated as DS1 and DS2. The false negative results are the most difficult to audit, as they require manual inspection of every wagon that the RCD system designated as 'clean' (the vast majority of the results) to identify any coal deposits that were judged to be significant (and hence should have triggered either a warning or an alarm). For this reason, only two months of results from DS2 (October 2013 and December 2014) were audited for false negatives.

The system accuracy for a given type of false indication can be determined from these results using the following formula:

$$
\text { Accuracy }=1-\frac{\text { number of false indications }}{\text { number of wagons }}
$$

Based on this formula the following accuracies were achieved across the audit periods:

- A $99.967 \%$ warning accuracy;

- A $99.971 \%$ alarm accuracy;

- A $99.988 \%$ false negative accuracy (for two periods of audit vehicles only);

- A $99.933 \%$ total system accuracy.

At the rate of eight trains of 100 wagons per day (typical for coal terminal A) this equates to:

- One false positive alarm every 35 trains, or every 4 days;

- One false negative every 83 trains, or every 10 days.

\subsubsection{Second Audit Results from Coal Terminal B}

The audit carried out at the second coal terminal covered a much longer period of time, and for this reason only alarms, not warnings, were examined. The accuracy results per period, and for the overall audit, were calculated using Equation (1) and are shown in Table 2. Note that no false negative alarms were identified during the audit. 
Table 2. Audit Results for Coal Terminal B Review.

\begin{tabular}{cccccc}
\hline Period & Trains & Vehicles $^{1}$ & Total Alarms & False Positive Alarms & Accuracy \\
\hline August 2015-December 2015 & 248 & 21,854 & 228 & 3 & $99.986 \%$ \\
January 2016-December 2016 & 800 & 78,963 & 387 & 13 & $99.984 \%$ \\
January 2017-December 2017 & 851 & 87,441 & 507 & 7 & $99.992 \%$ \\
All Periods & 1899 & 188,258 & 1122 & 23 & $99.988 \%$ \\
August 2015-December 2017 & & & & \\
\hline
\end{tabular}

${ }^{1}$ Vehicle counts include both locomotives and wagons.

At the rate of four trains of 100 wagons per day (typical for coal terminal B) this equates to approximately one false positive alarm every 82 trains, or every 20 days.

\section{Discussion}

The results for the original carryback project were of great interest to the industry, as they provided the first extensive, quantitative survey of the extent of the carryback problem. The histogram distributions shown in Figures 8 and 9 have some interesting features that deserve comment. The histograms show the frequency of wagons with varying volumes of coal carryback deposits. The large concentration of values in the first histogram bin therefore corresponds to wagons that are clean (effective volume of carryback near zero). The two distinct peaks above the lowest volume bins in Figure 8 correspond to characteristic deposit volumes associated with the two main wagon types scanned by the system, the three-door and four-door bottom dumping wagons. Similarly for Figure 9, the three subtle peaks are associated with different characteristic deposit patterns that occur in the wagon door regions.

The large spike in the average carryback volume per wagon that occurred due to rainy weather in the coal basin is unsurprising, as additional moisture is a well-known causative factor for sticky coal hang-ups [2]. The volume figure of 0.93 tonnes per wagon equates to almost an entire wagon per train that fails to unload: this is a significant productivity issue, quite apart from the safety and environmental concerns associated with the dispersion of residual coal. A recommendation of the original ACARP report was that development of an automated cleaning system be considered to reduce the levels of train wagon carryback.

The RCD results clearly demonstrate the high accuracy and reliability of system performance, with most alerts being due to true alarms and only a very minor quantity observed as false alarms. Observation of the data logs show that most false alarms occur due to one of the following three reasons:

1. A train stops for an extended period of time with the wagon lip directly underneath the RCD sensor (see Figure 10);

2. A locomotive is falsely classified as a wagon;

3. A noisy laser scanner signal resembles a legitimate hang-up profile.

The first situation is a known failure mode and may be addressed by the introduction of a train speed algorithm. The second situation may be addressed through refinement of the wagon/locomotive classifier. The third situation may be addressed through refinement of the laser scanner signal filtering algorithm.

The very small number of false negative cases-hang-ups that did not result in an alarm-were due to asymmetrical hang-ups with profiles closely resembling that of an empty wagon. 


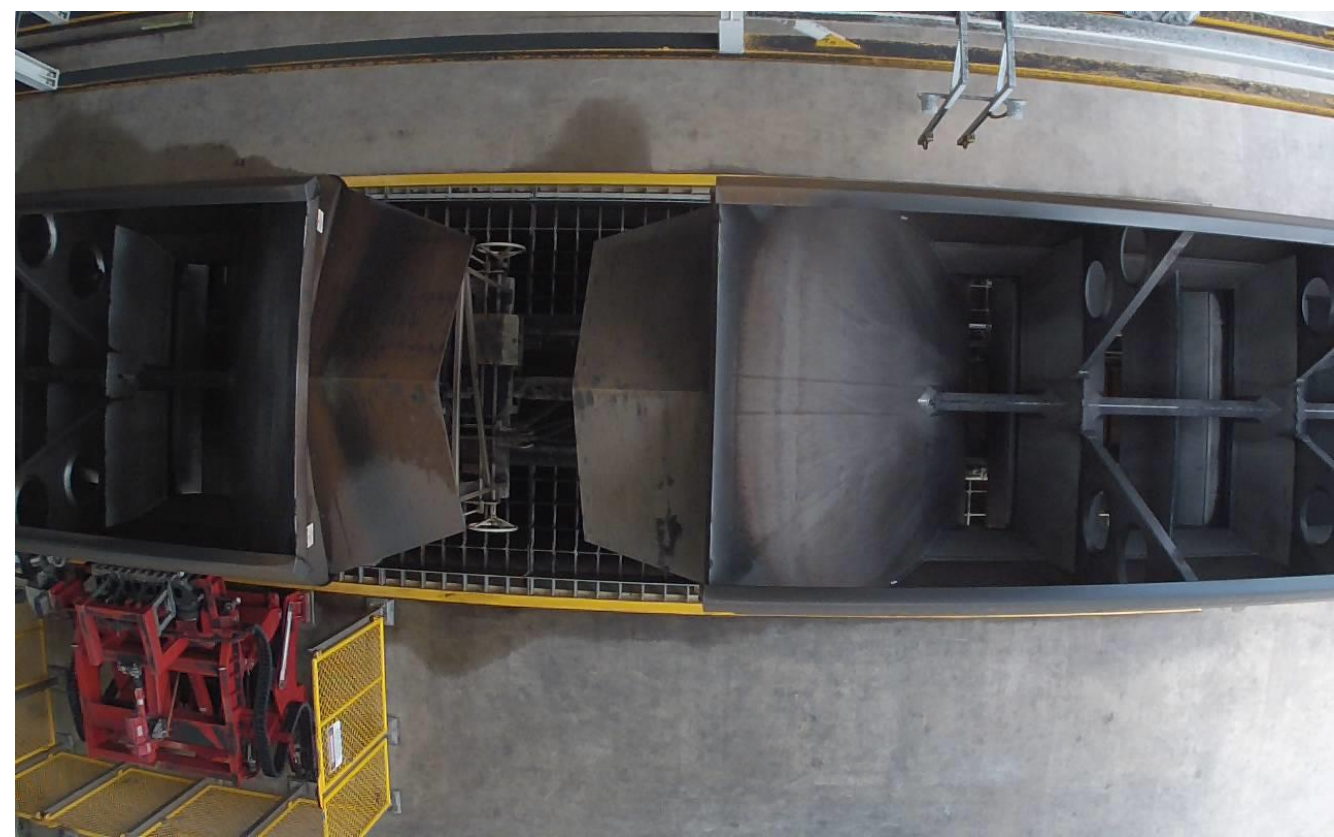

Figure 10. False alarm triggered by wagon paused directly under the laser scanner.

Each of these identified failure modes are very rare, and therefore they do not impede the successful operation of the RCD system. Nevertheless, since these audits, CSIRO has continued to improve the system performance. In particular, the following measures have been employed:

1. The speed detection algorithm was made more robust in order to avoid the case of false alarms due to train stoppages;

2. The laser scanner's signal filter was refined to remove noise in the signal that is characteristic of airborne coal dust. This dust contributes considerable noise to the signal when unloading coal during dry months;

3. The hang-up detection algorithm was revised to better identify hang-ups that closely resemble the profile of an empty wagon. This improvement was made without adversely affecting the false positive rate.

A further development that has occurred in parallel with the currently operational RCD system is the investigation of machine learning algorithms for hang-up detection [17]. While the existing RCD system has been extremely successful at detecting coal hang-ups, one ongoing challenge faced by the current system is an increase in the detection algorithm complexity as it has evolved over time. As new failure cases are detected, such as changes in the monitoring profile due to a new wagon type, a new iteration of the algorithm is introduced to overcome it. This progression has inevitably led to increasing complexity of the RCD processing logic, necessitating ongoing modifications and updates.

Coupled with this increase in complexity is an increase in the level of knowledge required to set up, configure and maintain the system by users. Machine Learning (ML) techniques offer a possible solution to both these problems:

1. Processing logic can be updated to overcome failure cases by allowing the system to learn from new data;

2. End user configuration and maintenance can be simplified by allowing users to directly incorporate new examples into the training data, thus retraining the system as required.

An initial study has been carried out using three different machine learning algorithms: K-Nearest Neighbour (a relatively simple ML technique which classifies a sample by comparing it to a certain number of neighbouring samples in the training set), Naïve Bayes (a classifier that applies Bayes' 
Theorem to feature vectors from each class label defined for the dataset), and a form of Neural Network (a network of artificial neurons arranged into multiple layers that progressively define probabilistic pathways for classification based on the use of training data). More details of these algorithms and their application can be found in the paper [17]. The results of this study are promising, and the integration of a selection of machine learning methods into the operational software is under consideration.

\section{Conclusions}

A detection system for remnant deposits in coal train wagons has been described. It has demonstrated its efficacy as both an auditing tool to provide information on the scale of carryback residue left in coal wagons, and as a real-time detection and warning system to assist with the management of large coal hangups that fail to discharge. The real-time system has achieved outstanding levels of accuracy and reliability during its period of deployment at multiple coal unloading stations in Australia's Bowen Basin region. It is now an integrated part of the unloading process, running on a 24/7 basis to enhance the efficiency of the coal terminal operation.

Although the RCD system is now a mature technology that has achieved the object of the research effort, scope remains for future enhancements. Ongoing work under investigation includes:

- Integration of machine learning algorithms into the real-time detection system;

- Transition of the system to a cloud-based processing paradigm to facilitate rapid software updates and support a move to a transaction-based model for commercialisation;

- Adaptation of the same technology to measurement of loaded coal wagons to provide information regarding wagon loading volumes and distribution.

Looking ahead, potential integration of the RCD system data and analysis with other elements of the coal value chain presents a significant opportunity to enhance the Digital Mine ecosystem.

Author Contributions: Conceptualization, methodology, investigation, project administration, formal analysis, writing - original draft creation, C.H. Software, validation, investigation, writing-review and editing, P.M. and C.H. All authors have read and agreed to the published version of the manuscript.

Funding: Part of this research was funded by ACARP, grant number C15071.

Acknowledgments: Jeremy Thompson and Craig James contributed technical and project management input for various stages of this research.

Conflicts of Interest: The authors declare no conflict of interest.

\section{References}

1. Plunkett, C.; Kayes, I.; Trieu, J.; Graham, J.; McMullen, P. Coal Spill Derailment Review of QR Coal Network. QR Netw. Access 2003, 197, 23-24.

2. O'Brien, G.; O'Brien, M.; Nemeth, D.; Graham, J.; Gnanananthan, S. Problems of Discharging Queensland Coals from Bottom Dump Rail Wagons, ACARP Project C10061 Final Report; Australian Coal Association Research Program: Brisbane, QLD, Australia, 2002.

3. O'Brien, G.; Paterson, S.; O'Brien, M.; Graham, J. Improved Coal Wagon Unloading by Reducing Loading Force, ACARP Project C12061 Final Report; Australian Coal Association Research Program: Brisbane, QLD, Australia, 2004.

4. Duff, E. Automated volume estimation of haul-truck loads. In Proceedings of the Australian Conference on Robotics and Automation, Melbourne, Australia, 30 August-1 September 2000.

5. Li, M.; Zhu, H.; Tang, C.; Li, Y. Efficient Laser-Based 3D SLAM in Real Time for Coal Mine Rescue Robots. In Proceedings of the IEEE 8th Annual International Conference on CYBER Technology in Automation, Control, and Intelligent Systems (CYBER), Tianjin, China, 19-23 July 2018.

6. Li, M.; Zhu, H.; You, S.; Wang, L.; Tang, C. Efficient Laser-Based 3D SLAM for Coal Mine Rescue Robots. IEEE Access 2018, 7, 14124-14138. [CrossRef] 
7. Saraf, N.M.; Hamid, J.R.A.; Halim, M.A.; Rasan, A.R.A.; Lin, S. Accuracy assessment of 3-dimensional LiDAR building extraction. In Proceedings of the IEEE 14th International Colloquium on Signal Processing \& Its Applications (CSPA), Batu Feringghi, Malaysia, 9-10 March 2018.

8. Amorim, L.L.; Mutz, F.; de Souza, A.F.; Badue, C.; Olveira-Santos, T. Simple and Effective Load Volume Estimation in Moving Trucks using LiDARs. In Proceedings of the 32nd SIBGRAPI Conference on Graphics, Patterns and Images (SIBGRAPI), Rio de Janeiro, Brazil, 28-31 October 2019.

9. Diosi, A.; Kleeman, L. Uncertainty of line segments extracted from static SICK PLS laser scans. In Proceedings of the Australasian Conference on Robotics and Automation, Brisbane, Australia, 1-3 December 2003.

10. Hargrave, C.; Valmadre, D. Trayscan: A Haul-Truck Load Measurement System; MineHaul: Perth, Australia, 2005.

11. Arnó, J.; Escola, A.; Vallès, J.M.; Llorens, J.; Sanz, R.; Masip, J.; Palacín, J.; Rosell-Polo, J.R. Leaf area index estimation in vineyards using a ground-based LiDAR scanner. Precis. Agric. 2012, 14, 290-306. [CrossRef]

12. Palacín, J.; Palleja, T.; Tresanchez, M.; Sanz, R.; Llorens, J.; Ribes-Dasi, M.; Masip, J.; Arnó, J.; Escola, A.; Rosell-Polo, J.R. Real-Time Tree-Foliage Surface Estimation Using a Ground Laser Scanner. IEEE Trans. Instrum. Meas. 2007, 56, 1377-1383. [CrossRef]

13. Ryde, J.; Hillier, N. Performance of laser and radar ranging devices in adverse environmental conditions. J. Field Robot. 2009, 26, 712-727. [CrossRef]

14. Einicke, G.A. High-Order Filtering of LIDAR Data to Assist Coal Shiploading. IEEE Trans. Aerospace Electron. Syst. 2017, 53, 1481-1488. [CrossRef]

15. Hargrave, C.; Haustein, K.; Thompson, J.; Einicke, G.; Plunkett, C.; Paterson, S. Reduction of Carry-Back and Coal Spillage in Rail Transport. Final Report, ACARP Project C15071; Australian Coal Association Research Program: Brisbane, QLD, Australia, 2008.

16. Hargrave, C.; Thompson, J.; Hainsworth, D. Remnant Coal Detection System for Coal Train Wagons. In Proceedings of the CORE2010 Conference on Rail Engineering, Wellington, New Zealand, 12-15 September 2010; pp. 203-211.

17. Thompson, J.; Hargrave, C.; Hainsworth, D.; James, C. Advanced Coal Wagon Monitoring using Machine Learning Algorithms. In Proceedings of the CORE2016 Conference on Rail Engineering, Melbourne, Victoria, 16-18 May 2016.

(C) 2020 by the authors. Licensee MDPI, Basel, Switzerland. This article is an open access article distributed under the terms and conditions of the Creative Commons Attribution (CC BY) license (http://creativecommons.org/licenses/by/4.0/). 